\title{
Incidence of end-stage renal disease in the elderly: a steadily rising global socioeconomic epidemic
}

\author{
Kosmas I. Paraskevas • Nikolaos Bessias • \\ Sotirios A. Koupidis • Effie Tziviskou • \\ Dimitri P. Mikhailidis • Dimitrios G. Oreopoulos
}

Received: 26 November 2009/Accepted: 30 November 2009/Published online: 18 December 2009

(C) Springer Science+Business Media, B.V. 2009

With age, the glomerular filtration rate and kidney function decline progressively [1, 2]. Due to the steadily increasing life expectancy around the world and the growing elderly population [3], the incidence of end-stage renal disease (ESRD) among the elderly is rising globally and should be expected to increase tremendously in the next few years/decades [4]. According to the 2007 United States Renal Data System (USRDS) Annual Data Report, more than

K. I. Paraskevas $(\bowtie) \cdot$ N. Bessias

Department of Vascular Surgery, Red Cross Hospital, 24, Al. Papagou Street, 14122 N. Iraklio, Athens, Greece e-mail: paraskevask@hotmail.com

S. A. Koupidis

Athens Dromokaition Psychiatric Hospital, Athens, Greece

\section{E. Tziviskou}

Department of Nephrology, "Henry Dunant" Hospital, Athens, Greece

D. P. Mikhailidis

Department of Clinical Biochemistry (Vascular Disease Prevention), Royal Free Hospital Campus, University College London Medical School, University College London (UCL), London, UK

D. G. Oreopoulos

Toronto Western Hospital, Toronto, Canada
106,000 new individuals began therapy for ESRD in 2005 (which was $2.0 \%$ more than in 2004), while the prevalent dialysis population increased to 340,000 patients (that is, $3.3 \%$ more than that in 2004) [4]. By 2004, there was a total of $1,371,000$ patients worldwide receiving dialysis treatment, with the number growing at an annual rate of 7\% [5, 6]. According to one forecast, the number of new patients with ESRD in the United States was expected to increase to 136,166 (range: 110,989164,550) by 2,015 [7]. More importantly, ESRD rates are rising most quickly among those persons aged $\geq 65$ [4]. According to the 2007 USRDS Annual Data Report [4], in 2005, the overall median age of new ESRD patients was 64.6 years. Although the incident rates between 2000 and 2005 have been relatively steady for most age groups, for patients $\geq 75$ years, the rate has grown by an astonishing $10 \%$, that is, from 1,570 to 1,725 patients per $1,000,000$ population [4]. According to a more recent report [8], the number of new octogenarians and nonagenarians starting dialysis increased from 7,054 persons/year in 1996 to 13,577 persons/year in 2003, corresponding to an average annual increase in dialysis initiation of $9.8 \%$ or an increase in the rate of dialysis initiation by $57 \%$ between 1996 and 2003 . These data clearly underline the importance of the growing epidemic of ESRD (particularly among the elderly) with its accompanying socioeconomic consequences.

A report from the Centers for Disease Control and Prevention showed that $61.4 \%$ of patients hospitalized 
with kidney disease in 2005 were $\geq 65$ years old. The same incidence was $49.9 \%$ in 1980 [9]. These data provide another proof of the rising incidence of chronic kidney disease (CKD) in the elderly. An increase of approximately $300 \%$ (from 19.3 to 56.2 per 10,000 population) occurred among persons aged 65-74 and an increase of approximately $350 \%$ (from 119.0 to 393.2 per 10,000 population) occurred among persons aged $\geq 75$ [9]. Kidney disease was the 9th leading cause of death in the United States in 2005 with nearly 26,000,000 persons having CKD, and another 20,000,000 being at increased risk for CKD [9]. ESRD causes approximately 85,000 deaths each year in the United States [9].

Several issues vary between younger and elderly patients. The possible vascular access options in elderly patients with ESRD should not be different from younger individuals [10]. However, access to renal transplantation is limited considerably by increasing age [11, 12]. Furthermore, older patients with CKD often report a worse quality-of-life than younger individuals [13, 14]; although elderly patients may often adjust to dialysis psychosocially better than younger individuals, the losses in physical and cognitive function may challenge the quality-oflife in a large percentage of them [13, 14]. In addition, CKD is associated with an increased risk for cardiovascular complications and cardiovascular disease mortality $[15,16]$. Furthermore, with growing age, the immune system is influenced in both qualitative and quantitative manner, making these patients more susceptible to infection and sepsis [17]. Probably, as a result of this, dialysis does not provide a survival benefit in elderly patients with ESRD and several co-morbidities $[15,16]$. All the above issues constitute important parameters when considering the effect of ESRD on economies around the globe. Patients with ESRD consume a considerable part of a country's budget on health; apparently, this percent is going to increase as the years go by. The total annual cost of treating ESRD patients in the United States was estimated to be $\$ 33$ billion in 2009 [9].

Several solutions to this growing global problem have been proposed, such as renal management clinics, where preventive measures (e.g. optimal management of diabetes mellitus and hypertension with drugs and life-style measures) to delay progression of renal failure should be expanded and applied to all patients with CKD stages 3 and 4 [18]. Also, home dialysis [19] and dialysis in nursing homes with extended care facilities [20] offer treatment for elderly patients without family support; these alternatives may prove to be better options than in-hospital dialysis. Another option for frail and physically dependent elderly patients with ESRD may be assisted automated peritoneal dialysis [21] or assisted peritoneal dialysis for the elderly [22]. These options utilize the assistance of home-care nurses and family members $[21,22]$. Patients with many comorbidities who cannot perform peritoneal exchange by themselves are offered considerable advantages with automated peritoneal dialysis since this limits home-care nurse visits to only two a day. Automated peritoneal dialysis keeps the patient's daytime free for nursing home activities, increases socialization and enables better rehabilitation that improves the quality-of-life of these individuals [22]. Some of these may contribute to the reduction in costs for dialysis patients. Others may actually increase costs. All these suggestions, however, need to be tested extensively before applying them to an organized health system.

Another important issue that needs to be taken into consideration is the cost-effectiveness of the dialysis method. A recent analysis of the cost of different dialysis modalities in UK hospitals showed that the most cost-effective modalities are continuous ambulatory peritoneal dialysis and automated peritoneal dialysis, with mean annual costs of $£ 15,570$ and $£ 21,655$, respectively. In contrast, hospital-based hemodialysis and satellite-unit-based hemodialysis were not cost-effective, with mean annual costs of $£ 35,023$ and $£ 32,669$, respectively [23]. A systematic review of the literature regarding the cost-effectiveness of dialysis treatment modalities demonstrated that hemodialysis is indeed a more expensive option than peritoneal dialysis [24].

In conclusion, the incidence of CKD stages 3-5 in the elderly is increasing around the world with every year. This increase holds considerable socioeconomic consequences for health economies worldwide. Thus, it is important to employ measures to reduce mortality rates in this population. There is an urgent need for a solution to this new epidemic by governments in collaboration with the Nephrology community around the world before its weight on global economy becomes unbearable. 


\section{References}

1. Zhou XJ, Saxena R, Liu Z et al (2008) Renal senescence in 2008: progress and challenges. Int Urol Nephrol 40:823839

2. Epstein M (1996) Aging and the kidney. J Am Soc Nephrol 7:1106-1122

3. Cassel CK (2000) Geriatrics for the 3rd millennium. Wien Klin Wochenschr 112:386-393

4. United States Renal Data System (USRDS) (2007) Annual data report. Available at: http://www.usrds.org/2007/pdf/ 02_incid_prev_07.pdf

5. Lysaght MJ (2002) Maintenance dialysis population dynamics: current trends and long-term implications. J Am Soc Nephrol 13(Suppl I):S37-S40

6. Grassmann A, Gioberge S, Moeller S et al (2005) ESRD patients in 2004: global overview of patient numbers, treatment modalities and associated trends. Nephrol Dial Transplant 20:2587-2593

7. Gilbertson DT, Liu J, Xue JL et al (2005) Projecting the number of patients with end-stage renal disease in the United States to the year 2015. J Am Soc Nephrol 16:3736-3741

8. Kurella M, Covinsky KE, Collins AJ et al (2007) Octogenarians and nonagenarians starting dialysis in the United States. Ann Intern Med 146:177-183

9. Centers for Disease Control, Prevention (CDC) (2008) Hospitalization discharge diagnoses for kidney disease United States, 1980-2005. MMWR Morb Mort Wkly Rep 57:309-312

10. Bessias N, Paraskevas KI, Tziviskou E et al (2008) Vascular access in elderly patients with end-stage renal disease. Int Urol Nephrol 40:1133-1142

11. Vamos EP, Novak M, Mucsi I (2009) Non-medical factors influencing access to renal transplantation. Int Urol Nephrol 41:607-616

12. Saxena R, Yu X, Giraldo M et al (2009) Renal transplantation in the elderly. Int Urol Nephrol 41:195-210
13. Tyrrell J, Paturel L, Cadec B et al (2005) Older patients undergoing dialysis treatment: cognitive functioning, depressive mood and health-related quality of life. Aging Ment Health 9:374-379

14. Kutner NG (2008) Promoting functioning and well-being in older CKD patients: review of recent evidence. Int Urol Nephrol 40:1151-1158

15. Banerjee D, Contreras G, Jaraba I et al (2009) Chronic kidney disease stages 3-5 and cardiovascular disease in the veterans affairs population. Int Urol Nephrol 41:443-451

16. Schlipak MG, Katz R, Kestenbaum B et al (2009) Rapid decline of kidney function increases cardiovascular risk in the elderly. J Am Soc Nephrol 20:2625-2630

17. Gorczynski RM, Terzioglu E (2008) Aging and the immune system. Int Urol Nephrol 40:1117-1125

18. Zhang AH, Zhong H, Tang W et al (2008) Establishing a renal management clinic in China: initiatives, challenges, and opportunities. Int Urol Nephrol 40:1053-1059

19. Oreopoulos DG, Thodis E, Passadakis P, Vargemezis V (2009) Home dialysis as a first option: a new paradigm. Int Urol Nephrol 41:595-605

20. Tong EM, Nissenson AR (2002) Dialysis in nursing homes. Semin Dial 15:103-106

21. Povlsen JV, Ivarsen P (2005) Assisted automated peritoneal dialysis (AAPD) for the functionally dependent and elderly patient. Perit Dial Int 25(suppl 3):S60-S63

22. Dimkovic N, Oreopoulos DG (2008) Assisted peritoneal dialysis as a method of choice for elderly with end-stage renal disease. Int Urol Nephrol 40:1143-1150

23. Baboolal K, McEwan P, Sondhi S et al (2008) The cost of renal dialysis in a UK setting-a multicentre study. Nephrol Dial Transplant 23:1982-1989

24. Just PM, Riella MC, Tschosik EA et al (2008) Economic evaluations of dialysis treatment modalities. Health Policy 86:163-180 